First publ. in: Animal Genetics 31 (2000), pp. 151-152

\section{Broad taxonomic applicability of microsatellites developed for the highly polymorphic neotropical cichlid, Amphilophus citrinellum K Noack ${ }^{1}$, A B Wilson ${ }^{2}$, A Meyer ${ }^{1,2}$}

${ }^{1}$ Department of Ecology and Evolution, State University of New York, Stony, Brook, New York, 11794-5245, U.S.A; ${ }^{2}$ Department of Biology, University of Konstanz, D-78457, Konstanz, Germany

Accepted 10 November 1999

Neotropical cichlids are some of the most important food fishes of Central America ${ }^{1}$. In addition to its important economic role as part of the freshwater fishery, the Midas cichlid, Amphilophus citrinellum, exhibits a high level of intraspecific variation in both coloration $^{1}$ and pharyngeal jaw morphology ${ }^{2}$, which has made it a model species for the study of incipient, possibly, sympatric speciation $^{2,3}$. While behavioural and ecological studies of $A$. citrinellum have been numerous and thorough, investigations of the genetic variation of this species are almost completely missing. We have previously found exceedingly low levels of variation in the mitochondrial control region and cytochrome $b$ gene which suggests a recent origin of the species (Meyer et al. unpublished data).

While a suite of microsatellite loci have been developed for African cichlids, these microsatellite primer sets have proven largely ineffective in amplifying Neotropical species ${ }^{4,5,6}$. In this study, we describe the identification of six di-and tri-nucleotide microsatellite loci in A. citrinellum that can also be amplified in many species of cichlids both from the Neotropics and the Old World.

Genomic DNA was extracted from a single A. citrinellum specimen collected from Lake Nicaragua using a previously published extraction protocol ${ }^{7}$. EcoR1-digested DNA fragments were ligated to pUC18 (Gibco BRL) and transformed into SURE cells (Stratagene). The resulting library was screened with a $\left[\gamma^{32}{ }^{32} \mathrm{P}\right.$-ATP end-labeled $(\mathrm{GT})_{10}$ oligonucleotide using standard hybridization techniques. Twenty-five positive clones of 300-1000 bp were sequenced using a Taq Dye-Deoxy Termination Cycle Kit (ABI - following manufacturer's recommendations) and analyzed with an ABI 373 Stretch DNA automated sequencer. Primer sets were developed for six of the 25 clones containing GT-microsatellites and adequate single-copy flanking DNA for primer design.

Amplification of the six microsatellite loci was carried out in a Geneamp 9700 Thermocycler (ABI) using $25 \mu \mathrm{l}$ reaction volumes (Tris $67 \mathrm{~mm}$, pH. 8.8; $1.5 \mathrm{~mm} \mathrm{MgCl}_{2} ; 0.4 \mathrm{~mm}$ of each dNTP; $75 \mathrm{ng}$ of each primer and one unit of AmpliTaq DNA Polymerase (PerkinElmer Cetus)). Forward primers were labelled with tetrachloro-6carboxyfluorescin (TET). Amplification reaction conditions consisted of an initial denaturing step of $3 \mathrm{~min}$ at $94^{\circ} \mathrm{C}$ followed by 30 cycles of $94^{\circ} \mathrm{C}$ for $1 \mathrm{~min}$, an optimised annealing temperature (see Table 1) for $30 \mathrm{~s}$, and $72^{\circ} \mathrm{C}$ for $1 \mathrm{~min}$. PCR products were visualised on agarose gels stained with ethidium bromide and diluted according to their strength. One microlitre of each sample was then mixed with $2 \mu \mathrm{l}$ formamide and $0.5 \mu \mathrm{l}$ each of size standard (GeneScan TAMRA-500, Applied Biosystems) and TAMRA buffer. The samples were denatured at $98^{\circ} \mathrm{C}$ for two minutes, loaded on a 5\% denaturing 19:1 acrylamide:bisacrylamide gel and analysed using an ABI 373 A Stretch Automated Sequencer. Allele sizes were determined by the GeneScan software (Perkin Elmer) based on comparison of migration distances with the TAMRA ladder fragments of known size within each lane.

The six microsatellite loci were amplified in a total of $140 \mathrm{~A}$ citrinellum individuals from four lacustrine populations in Nicaragua. Levels of intraspecific variation varied considerably amongst loci, with allele numbers at each locus ranging from 1 to 26 and observed heterozygosity ranging between $0 \cdot 000$ and $0 \cdot 664$.

In addition to a high overall level of intraspecific variation, these six microsatellite loci have also proven useful in a broad taxonomic array of cichlid species (Table 2). In contrast to the majority of microsatellites identified in African species that fail to amplify Neotropical cichlids ${ }^{5}$, the present six microsatellite loci amplify both Neotropical and Old World species. These markers may prove effective in a further taxonomic clarification of relationships between New World and Old World cichlids.

The high intraspecific variation of these microsatellites makes them ideally suited to a detailed molecular investigation of observed anatomical and behavioural polymorphism in A. citrinellum and to molecular characterisation of wild stocks of the species. At the same time, the broad taxonomic applicability of these markers offers an opportunity to further examine evolutionary questions related to the rapid speciation of cichlid fishes.

Table 1 Primer sequences and core repeat structure for Amphilophus cichlasoma microsatellites. All loci were tested on 140 individuals from four lacustrine populations in Nicaragua

\begin{tabular}{|c|c|c|c|c|c|c|c|}
\hline Locus & $\begin{array}{l}\text { No. of } \\
\text { alleles }\end{array}$ & $\mathrm{H}_{\mathrm{O}}$ & $\mathrm{H}_{\mathrm{E}}$ & Primer sequence $\left(5^{\prime}-3^{\prime}\right)$ & Cloned repeat motif & $\begin{array}{l}\text { Size of } \\
\text { sequenced } \\
\text { product (bp) }\end{array}$ & $\begin{array}{l}\text { Annealing } \\
\text { temperature } \\
\left({ }^{\circ} \mathrm{C}\right)\end{array}$ \\
\hline$\overline{\text { Acit1 }}$ & 6 & $0 \cdot 101$ & $0 \cdot 487$ & $\begin{array}{l}\text { F AAA TGA GTT CAG CGA TGG CTG AG } \\
\mathbf{R} \text { TGC ACA TCA TGT CCG CCG AAC A }\end{array}$ & $(\mathrm{AG})_{11}$ & $168-174$ & 49 \\
\hline Acit2 & 26 & $0 \cdot 593$ & $0 \cdot 926$ & $\begin{array}{l}\text { F GGC ACT GAG GAT TTA TAT TAC AGG } \\
\mathbf{R} \text { GAG GTC CAG CTG AGA ACA GGG }\end{array}$ & $(G T)_{35}$ & $184-232$ & 52 \\
\hline Acit 3 & 18 & $0 \cdot 664$ & $0 \cdot 905$ & $\begin{array}{l}\text { F CTT AAG GTG TAC CTG CTT AGC } \\
\mathbf{R} \text { GAG TGG GAA GAC AGA TGT TGA GG }\end{array}$ & $(G T)_{32}$ & 161-195 & 51 \\
\hline Acit4 & 15 & 0.593 & $0 \cdot 829$ & $\begin{array}{l}\mathbf{F} \text { CCT TCC TAC TAG TTA GTC TTT CAC } \\
\mathbf{R} \text { CAC ATA GCA CAG TGC ATT CAC CC }\end{array}$ & $(G T)_{22}$ & $347-375$ & 49 \\
\hline Acit5 & 1 & $0 \cdot 000$ & $0 \cdot 000$ & $\begin{array}{l}\mathbf{F} \text { GCC GCA CCC TCA TTA TCC TCA C } \\
\mathbf{R} \text { GTG ACT CCA ACG TGT AGC TTC C }\end{array}$ & $(\mathrm{AGC})_{8}$ & 157 & 52 \\
\hline Acit6 & 1 & $0 \cdot 000$ & $0 \cdot 000$ & $\begin{array}{l}\text { F GAA TTC ACA AAG GCC AAT CCT AC } \\
\mathbf{R} \text { GGA TAC TGA GCA TGA CAA TAA GC }\end{array}$ & $(\mathrm{CA})_{9}(\mathrm{TA})_{16}(\mathrm{TG})_{18}(\mathrm{TTA})_{3}$ & 268 & 50 \\
\hline
\end{tabular}

Genbank accession numbers: AF237713-AF237718.

$\mathrm{H}_{\mathrm{O}}=$ observed heterozygosity; $\mathrm{H}_{\mathrm{E}}=$ expected heterozygosity. 
Acknowledgements: We thank Rafael Zardoya for technical assistance with the preparation of the genomic library. This work was partially supported by grants from the U.S. National Science Foundation (BSR-9107838, BSR-9119867, DEB-9615178) the University of Konstanz, the DFG, the Fond der Chemischen Industrie to AM and a NSERC PGSB scholarship to ABW.

Table 2 Success of cross-species amplification of Amphilophus citrinellum microsatellite loci

\begin{tabular}{|c|c|c|c|c|c|c|}
\hline & Acit1 & Acit2 & Acit3 & Acit4 & Acit5 & Acit6 \\
\hline \multicolumn{7}{|l|}{ Neotropics } \\
\hline Amphilophus citrinellum & + & + & + & + & + & + \\
\hline Cichla cichla & + & + & + & + & + & + \\
\hline Crenicichla saxatilis & + & + & + & + & $?$ & + \\
\hline East Africa & & & & & & \\
\hline $\begin{array}{l}\text { Astatoreochromis alluaudi } \\
\text { West Africa }\end{array}$ & + & - & + & + & + & + \\
\hline $\begin{array}{l}\text { Hemichromis bimaculatus } \\
\text { Madagascar and India }\end{array}$ & + & - & + & - & - & + \\
\hline Etroplus maculatus & - & + & - & + & $?$ & - \\
\hline
\end{tabular}

(+) product; (-) no obvious product (?) product of questionable size.

References

1 Barlow, G.W. (1976) The Midas cichlid in Nicaragua. In: Investigations of the Ichthyofauna of Nicaraguan Lakes (ed. Thorson, T.B.), pp. 333-58 University of Nebraska Press, Lincoln,

NB.

2 Meyer, A. (1990) Biol J Linnean Soc 39, 279-99.

3 McKaye, K.R. (1980) Environ Biol Fishes 5, 75-8.

4 Kellogg, K.A. et al. (1995) Proc R Soc Lond Series B 260, 79-84.

5 Zardoya, R. et al. (1996) Proc R Soc Lond Series B 263, 1589-98.

6 Van Oppen, M.J.H. et al. (1997) Mol Ecol 6, 387-8.

7 Karl, S.A. \& Avise, J.C. (1993) Mol Biol Evolut 10, 342-61.

Correspondence: Axel Meyer (e-mail:

axel.meyer@uni-konstanz.de) 